\section{Study of Genetic Mutations in Gene ZAP70 in Inducate ZAP70- Related Severe Combined Immuno Deficiency Syndrome}

Journal of

Vaccine \&

\section{Immunotechnology}

\author{
Shahin Asadi* \\ Department of Medical Genetics, Molecular Medicine Genetics \\ Harvard University, Iran
}

\section{Address for Correspondence}

Shahin Asadi, Department of Medical Genetics, Molecular Medicine Genetics Harvard University, Director of the Division of Medical Genetics and Molecular Research, Division of Medical Genetics and Molecular Pathology Research, Massachusetts, Iran, E-mail: shahin.asadi1985@gmail.com

Keywords: ZAP70-SCID syndrome; ZAP70 gene; Immune system

\begin{abstract}
ZAP70-SCID syndrome is a hereditary genetic disorder that damages the immune system. Children with SCID have virtually no immune system against bacterial, viral, and fungal infections. SCID is a group of very rare, life-threatening diseases that are present at birth. The disease causes the child to have very little or no immune system. As a result, the child's body is unable to fight off infections. This disease process is also known as the "boy in the bubble" syndrome because living in the normal environment can prove fatal to these children.
\end{abstract}

Children with this rare, inherited disease become very ill with illnesses such as pneumonia, meningitis, and chickenpox and can die within the first year of their life. With new advances in treatments, however, children with SCID can be successfully treated.

ZAP70-SCID syndrome is caused by the mutation of the ZAP70 gene, which is based on the long arm of chromosome number 2 as $2 \mathrm{q} 11.2$.

\section{Generalizations of ZAP70 related SCID- syndrome (ZAP70-SCID)}

ZAP70-SCID syndrome is a hereditary genetic disorder that damages the immune system. SCID-dependent ZAP70 syndrome is one of the forms of severe immunosuppression that is caused by several genetic causes [1]. Severe Combined Immunodeficiency (SCID) comprises a group of rare monogenic primary immunodeficiency disorders characterized by a lack of functional peripheral $\mathrm{T}$ lymphocytes resulting in early-onset severe respiratory infections and failure to thrive. They are classified according to immunological phenotype into SCID with absence of T cells but presence of B cells (T-, B+, SCID) or SCID with absence of both (T-,B- SCID) (see these terms). Both of these groups include several forms, with or without natural killer (NK) cells [1].

Clinical symptoms of ZAP70 related SCID- syndrome (ZAP70SCID)

Children with SCID have virtually no immune system against bacterial, viral, and fungal infections. They are susceptible to frequent and persistent infections that can be very serious and life threatening. Most microorganisms that cause infection in people with this disorder are described as opportunistic microorganisms, because they usually do not cause disease in healthy people. Infants with ZAP70-SCID typically have pneumonia, chronic diarrhea, and extensive rash (rash). They also grow much slower than healthy children. If the immune system of these children does not have the ability to fight infection, they usually die one or two years after the
Submission: 02 March, 2019

Accepted: 03 April, 2019

Published: 05 April, 2019

Copyright: (c) 2019 Asadi S, et al. This is an open access article distributed under the Creative Commons Attribution License, which permits unrestricted use, distribution, and reproduction in any medium, provided the original work is properly cited.

onset of infections. Most people with ZAP70-SCID syndrome are diagnosed in the first 6 months of life [2].

\section{Etiology of ZAP70 related SCID- syndrome (ZAP70-SCID)}

ZAP70-SCID syndrome is caused by the mutation of the ZAP70 gene, which is based on the long arm of chromosome number 2 as $2 \mathrm{q} 11.2$. The gene provides instructions for the synthesis of a protein called zeta chain protein kinase. This protein is part of the signaling pathway that creates and activates immune cells called T cells. T cells detect external material and protect the body from infection (Figure 1) [3].

The ZAP70 gene is important for the development and function of several $\mathrm{T}$ cell types. These include cytotoxic $\mathrm{T}$ cells (CD8+ T cells) whose function involves destroying virus-infected cells. The ZAP70 gene is also involved in the activation of T helper cells (CD4+ T cells). These cells directly contribute to the immune system by influencing the activities of other immune cells [4].

The mutation in the ZAP70 gene blocks the production of Zetalinked protein kinase, or leads to a protein that is unstable and cannot function. Loss of zeta-functional protein kinase results in the absence of CD8+ T cells and excessive inactivation of CD4+ T cells. The deficiency of active $\mathrm{T}$ cells causes those who have ZAP70-dependent SCID (ZAP70-SCID) to become more susceptible to infection [5]

ZAP70-SCID syndrome follows an autosomal recessive hereditary pattern. Therefore, in order to produce this syndrome, two copies of the mutated gene ZAP70 (one parent and one mother) are needed, and the chance of having a child with this syndrome in an autosomal

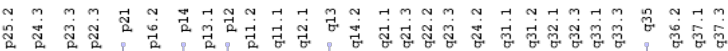

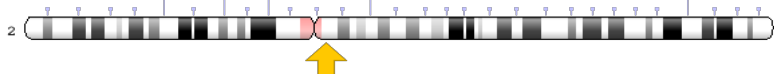

Figure 1: Schematic view of chromosome number 2, in which the ZAP70 gene is located in the long arm of this chromosome $2 q 11.2$ 


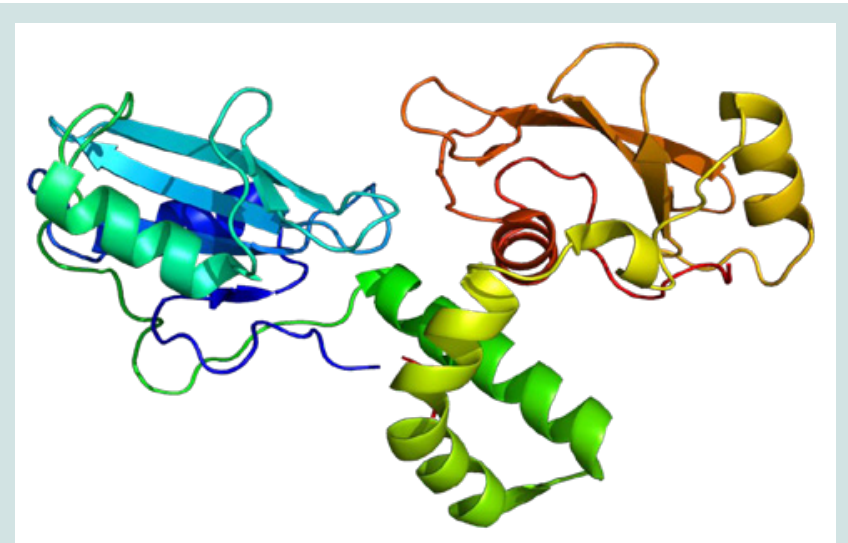

Figure 2: Schematic of ZAP70 protein packet structure.

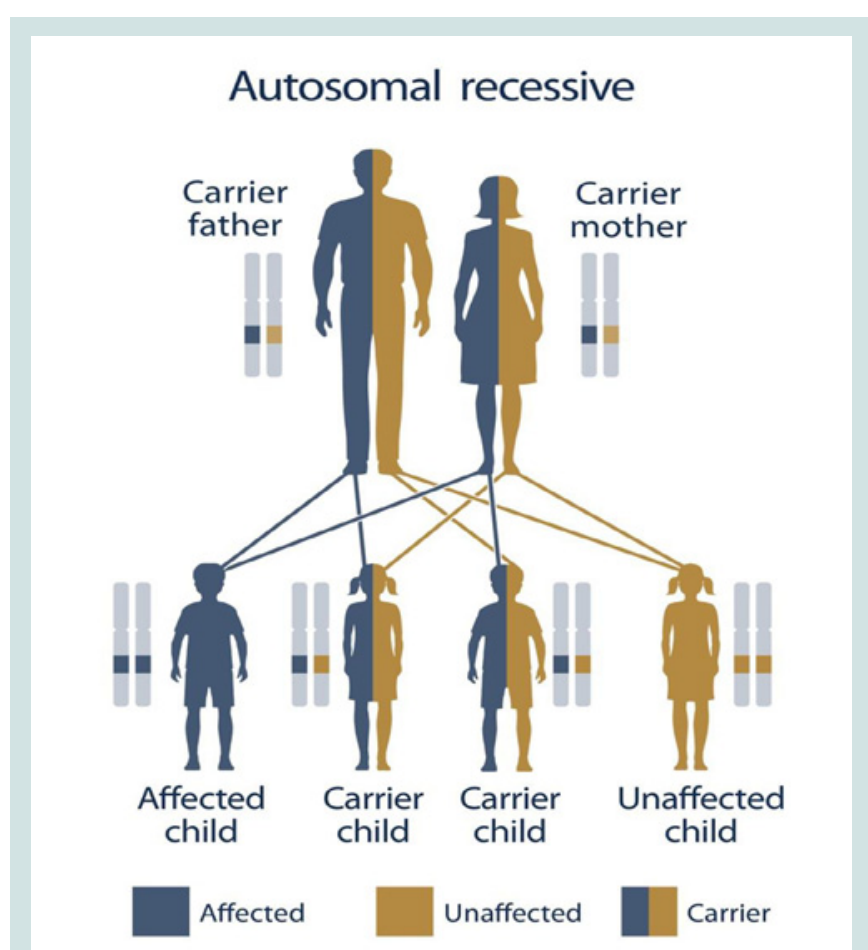

Figure 3: Schematic view of autosomal recessive hereditary pattern followed by ZAP70-SCID syndrome.

recessive state is $25 \%$ for each pregnancy [6].

The prevalence of ZAP70 related SCID- syndrome (ZAP70-SCID)

ZAP70-SCID syndrome is a rare genetic disorder that has been reported in about 20 cases of this syndrome from around the world in medical literature. The incidence of SCID disorder is approximately 1 in 50,000 people [7]. Overall incidence is estimated at about $1 / 50,000$ live births, with regional differences and higher incidences among populations with a higher consanguinity rate. The disease affects more males because of the X-linked variant (SCID T-B+ due to gamma chain deficiency; see this term) that represents about $30 \%$ of SCID cases in Western countries.

\section{Detection of ZAP70 related SCID- syndrome (ZAP70-SCID)}

The ZAP70-SCID syndrome is diagnosed based on the clinical and clinical findings of the patients and some pathological tests. The most accurate method for detecting this syndrome is the molecular genetic testing of the ZAP70 gene to investigate the presence of possible mutations [7]. Early diagnosis, before the infant has had a chance to develop any infections, is very valuable since bone marrow transplants given in the first three months of life have a $94 \%$ success rate. In fact, screening newborns to detect SCID soon after birth has been made possible because of recent scientific advances. Approximately half of the babies born in the U.S. are now being screened for SCID [7]. The Genetic Testing Registry (GTR) provides information about the genetic tests for this condition. The intended audience for the GTR is health care providers and researchers. Patients and consumers with specific questions about a genetic test should contact a health care provider or a genetics professional [7]. An Action (ACT) sheet is available for this condition that describes the short-term actions a health professional should follow when an infant has a positive newborn screening result. ACT sheets were developed by experts in collaboration with the American college of medical genetics. Without treatment SCID usually results in severe infection and death in children by age of 2 . When performed from an HLA-identical sibling, and in the first few months of life, HSCT can result in a greater than $90 \%$ long-term survival rate (Figure 2) [7].

Therapeutic routes of ZAP70 related SCID- syndrome (ZAP70SCID)

The ZAP70-SCID syndrome treatment and management strategy is symptomatic and supportive. Treatment may be done by a team of experts, including immunologist, dietitian, pulmonary specialist and other health care professionals. There is no standard treatment for this syndrome, and all clinical interventions are designed to reduce the suffering of the sufferers. Genetic counseling is also a special place for all parents who want a healthy baby [7]. The child will be admitted to a room or an area with 'filtered air' (to remove germs). He or she will be confined to this room and will not be able to mix with other children or go to the ward playroom. Parents are able to stay with their child and will be encouraged to continue to feed, care for and play with him or her as much as they want. Visitors will be kept to a minimum, and no one who has an infection will be allowed to visit. Parents will be told about the ways that they can avoid passing on infection, such as washing their hands thoroughly (Figure 3) [7].

Further blood tests will be performed to confirm the diagnosis and type of SCID. More specialized tests will subsequently be carried out to determine the precise genetic abnormality. Other investigations will also be necessary to identify any undetected infection, including chest $\mathrm{x}$-rays, scans and tests on samples of blood, urine, faeces and mucus from the throat [7].

\section{Discussion and Conclusion}

ZAP70-SCID syndrome is a hereditary genetic disorder that damages the immune system. Children with SCID have virtually no immune system against bacterial, viral, and fungal infections. ZAP70SCID syndrome is caused by the mutation of the ZAP70 gene, which is based on the long arm of chromosome number 2 as $2 \mathrm{q} 11.2$. There is 
Citation: Asadi S. Study of Genetic Mutations in Gene ZAP70 in Inducate ZAP70-Related Severe Combined Immuno Deficiency Syndrome. J Vaccine Immunotechnology. 2019;4(1): 3.

ISSN: $2377-6668$

no standard treatment for this syndrome, and all clinical interventions are designed to reduce the suffering of the sufferers.

\section{References}

1. Elder ME (1997) SCID due to ZAP-70 deficiency. J Pediatr Hematol Oncol 19: $546-550$

2. Elder ME (2000) T-cell immunodeficiencies. Pediatr Clin North Am 47: 1253 1274.

3. Grunebaum E, Sharfe N, Roifman CM (2006) Human T cell immunodeficiency: when signal transduction goes wrong. Immunol Res 35: 117-126.
4. Picard C, Dogniaux S, Chemin K, Maciorowski Z, Lim A, et al. (2009) Hypomorphic mutation of ZAP70 in human results in a late onset immunodeficiency and no autoimmunity. Eur J Immunol 39: 1966-1976.

5. Roifman CM, Dadi H, Somech R, Nahum A, Sharfe N (2010) Characterization of $\zeta$-associated protein, $70 \mathrm{kd}$ (ZAP70)-deficient human lymphocytes. J Allergy Clin Immunol 126: 1226-1233.

6. Turul T, Tezcan I, Artac H, de Bruin-Versteeg S, Barendregt BH, et al. (2009) Clinical heterogeneity can hamper the diagnosis of patients with ZAP70 deficiency. Eur J Pediatr 168: 87-93.

7. Walkovich K, Vander Lugt M (2017) ZAP70-Related Combined Immunodeficiency. In: Pagon RA, Adam MP, Ardinger HH, Wallace SE, Amemiya A, et al. (Eds). GeneReviews ${ }^{\circledR}$. Seattle (WA): University of Washington, Seattle; 1993-2017. 